\title{
Pintura, fotografia e memória na produção artística de Paulo Gaiad
}

\section{Painting, photography and memory in the artistic production of Paulo Gaiad}

\author{
Wagner Jonasson da Costa Lima \\ Doutor em Artes Visuais pela Universidade do Estado de Santa Catarina (UDESC) - \\ wagnerjonasson@hotmail.com-orcid.org/0000-0001-6983-8651
}

\begin{abstract}
Resumo
O texto aborda a relação estabelecida entre pintura e fotografia na produção artística de Paulo Gaiad, procurando analisar como a associação entre esses diferentes meios de expressão, ou paradigmas da imagem, contribuiu para a constituição do projeto poético do artista, projeto esse baseado, conforme suas declarações, no fenômeno da "memória". Para tanto, o artigo concentra-se na fatura de determinados trabalhos de Gaiad, especialmente aqueles pertencentes às séries As Paredes que me Cercam, A divina comédia, Memórias da cozinha e Estudos de luz e sombra. Nesse conjunto de quadros, pode-se sugerir que o artista procurou materializar a operação da memória, vista como processo de recriação do ocorrido, por meio da justaposição entre o pictórico e o fotográfico. Para esse fim, cabe complementar, também convocou e atualizou gêneros tradicionais, como a paisagem e a natureza-morta. Nessa lógica, os modos operativos de Gaiad integram um cenário, o da arte contemporânea, no qual as relações entre os diferentes meios são de comunhão e não de exclusão.
\end{abstract}

Palavras-chave: Memória na arte; Gaiad, Paulo Renato, 1953-; Fotografia artística; Natureza-morta na arte.

\begin{abstract}
The text addresses the relationship established between painting and photography in the artistic production of Paulo Gaiad, seeking to analyze how the association between these different means of expression or image paradigms contributed to the constitution of this artist's poetic project, that is, a project based, according to his statements, in the phenomenon of "memory". To this end, the study focuses on analyzing certain works by Gaiad, especially those belonging to the series As Paredes que me Cercam, A divina comédia, Memórias da cozinha e Estudos de luz e sombra. In this set of pictures, it may be suggested that the artist sought to materialize the operation of memory, seen as a process of recreating what had happened, through the juxtaposition between the pictorial and the photographic. To this end, it is worth complementing that he also used and updated traditional genres, such as landscape and still life. In this logic, the Gaiad's operating modes integrate a scenario, the contemporary art, in which the relations between the different means are of communion and not of exclusion.
\end{abstract}

Keywords: Memory in art; Gaiad, Paulo Renato, 1953-; Photography, Artistic; Still-life painting.

Recebido em: 04/05/2021

Aceito em: 19/07/2021 


\section{INTRODUÇÃO}

No decorrer do século XX, diferentes artistas adotaram a fotografia como motivo e material para a pintura. Na década de 1950, Robert Rauschenberg (1925-2008), movido pelas colagens de Kurt Schwitters (1887-1948), introduziu imagens fotomecânicas em seus quadros, como cartõespostais e anúncios de revista, distanciando-se com isso da "doutrina formalista segundo a qual a pintura aspira a uma síntese cada vez mais restrita dos elementos que a compõem" (STEINBERG, 2008, p. 110). A partir do uso de materiais não tradicionais, bidimensionais e tridimensionais, o artista norte-americano conferiu, na visão de Leo Steinberg, outra orientação para a pintura, uma guinada do plano vertical, fundado pelo Renascimento, para o plano horizontal ou "de tipo flatbed", que "faz sua alusão simbólica a superfícies duras, como tampos de mesa, chão de ateliê, diagramas, quadros de aviso" (STEINBERG, 2008. p. 117). O plano de tipo flatbed, para Steinberg, expressaria uma transformação importante no tema da arte: a mudança da natureza para a cultura.

Posteriormente, o chamado "neoexpressionismo", tendência pictórica que despontou entre final da década de 1970 e início da seguinte, também estabeleceu diálogo próprio com o universo de imagens oferecidas pela fotografia e veiculadas pelos meios de comunicação de massa. Naquele momento, diversos artistas, além de reabilitar a pintura, depois das propostas de desmaterialização da arte, dedicaram-se à "elaboração de outros sistemas visuais significativos, criados a partir da conjugação de imagens e procedimentos linguísticos preexistentes" (CHIARELLI, 2001, p. 257). A fotografia e as suas imagens comparecem na produção de Anselm Kiefer (1945-), artista alemão cujo trabalho inicial aliava símbolos da cultura germânica, apossados pelo nazismo, com uma ênfase na densidade da superfície pictórica, derivada dos expressionismos da primeira metade do século XX (HUYSSEN, 1996). Frequentemente, a imagem fotográfica, incorporada às telas de Kiefer, juntamente com outros objetos, sofreu a ação de ampla variedade de materiais.

É possível identificar na produção de Paulo Gaiad (1953-2016) essa estreita relação entre pintura e fotografia que assinalou os trabalhos de Rauschenberg e Kiefer. Com formação em arquitetura e urbanismo, Gaiad iniciou carreira artística na década de 1980, depois de fixar residência em Florianópolis - SC. Realizou a primeira exposição individual em 1987 e, a partir de 2000, associou seguidamente pintura e fotografia, meios tidos como paradigmas da imagem. Conforme Santaella e Nöth (1998, p. 163), a pintura decorre de "processos artesanais de criação", enquanto a fotografia de "processos automáticos de captação". Logo, essas imagens dispõem de 
modos próprios de produção, armazenamento, transmissão e recepção. Porém, a mistura e a justaposição de tais paradigmas encontram-se nos fenômenos de hibridização e de mestiçagem das artes (CATTANI, 2006). À semelhança de vários artistas contemporâneos, Gaiad considerou, na elaboração de suas obras, a coexistência entre a pintura e a fotografia, entre o artesanal e o automático.

Entretanto, os trabalhos de Gaiad constituem um projeto poético particular, orientado, de acordo com suas declarações, para a "memória". Como apontou o artista, "a base do meu trabalho é praticamente a memória. [...] Eu vou recolhendo memórias para depois transformar isso na minha obra. [...] Então nesse processo eu trabalho também a questão do material" (GAIAD, 2015). Tendo em vista essa observação, pode-se interrogar qual é a relação estabelecida entre pintura, fotografia e memória na produção de Paulo Gaiad. Como resposta suposta e provisória, sugere-se que, em muitos dos seus quadros, o artista buscou corporificar, por meio do encontro entre recursos da pintura e da fotografia, a operação da memória, operação essa compreendida não como recuperação e sim como recriação do passado. Para esse propósito, convém acrescentar, Gaiad utilizou não só a combinação de diferentes meios, mas também a tradição da pintura, valendo-se de gêneros como a paisagem e a natureza-morta.

Para analisar a relação estabelecida entre pintura, fotografia e memória na produção de Paulo Gaiad, o texto concentra-se na fatura de trabalhos pertencentes às séries As Paredes que me Cercam, A divina comédia, Memórias da cozinha e Estudos de luz e sombra. Por "fatura", entendese aqui a maneira de operar de determinado artista, que pode ser percebida, em parte, a partir das evidências da elaboração do trabalho artístico, a sua textura de superfície, resultante do entrelaçamento entre meios e procedimentos escolhidos em certa circunstância. Sendo assim, aborda-se a obra de arte como produto da atividade intencional, isto é, como produto de um "projeto poético" (SALLES, 2011), embora contra um pano de fundo de tradições artísticas. Logo, antes de tratar da fatura de Gaiad, busca-se brevemente apresentar a correspondência entre pintura, fotografia e memória, assim como, em seguida, situar o artista brasileiro. Por fim, convém salientar que o presente texto, derivado de roda de conversa ocorrida em 2016 no Museu da Escola 
Catarinense $(\mathrm{Mesc})^{1}$, não se propõe esgotar o assunto, mas lançar apontamentos para investigações futuras.

\section{PINTURA, FOTOGRAFIA E MEMÓRIA}

Desde a sua invenção, a fotografia, considerada a primeira imagem técnica que prescinde da mão do artista, diferenciou-se das artes tradicionais, notadamente da pintura. Surgida quase simultaneamente na França e na Inglaterra, na era do maquinismo, a fotografia determinou, segundo André Rouillé (2009), um novo protocolo de produção de imagens. Se a imagem pictórica, resultante de operações manuais, surge durante processo de fabricação, a imagem fotográfica, resultante de operações químicas, surge de uma só vez, em espaço adaptado para isso, o laboratório. Em lugar de representar, a fotografia situou-se como máquina de capturar. Dessa maneira, como máquina de produzir imagens de captura, a fotografia foi acusada de não omitir nada, diversamente da pintura, cuja elaboração envolveria seleção. A partir de meados do século XIX, e no decurso de mais de um século, a oposição entre pintura e fotografia pronunciou-se em distinções entre construção e captação, entre mão do artista e máquina do operador, entre arte e documento.

Percebida como documento, ou como "testemunho de uma realidade que existiu" (GONZÁLEZ FLORES, 2011, p. 123), a fotografia funcionaria como equivalente palpável da memória. De acordo com Laura González Flores (2011, p. 125), a memória, até o século XIX, foi explicada "como uma seleção mecânica de dados e imagens que são concebidos como oriundos de um arquivo/passado e levados a um exame/presente". Por sua vez, a fotografia, no seu uso cotidiano, recebeu a classificação de meio referencial e indicial, concepção que concorda com a interpretação oferecida por autores como Roland Barthes (1915-1980) e Susan Sontag (1933-2004). Nessa visão, a essência da fotografia se depreende do que sucedeu, ou seja, "sem objeto-existência banhado pela luz não há imagem-testemunho" (GONZÁLEZ FLORES, 2011, p. 123). Diante disso, memória e fotografia operariam de modo semelhante, deslocando imagens do passado para o presente, a memória faria isso mentalmente, enquanto a fotografia materialmente.

\footnotetext{
${ }^{1}$ Roda de conversa intitulada "Conversas sobre Paulo", ocorrida em 19 de abril de 2016 no Museu da Escola Catarinense (Mesc), com a participação dos seguintes convidados: Profa. Dra. Sandra Makowiecky, Prof. Dr. Antonio Vargas, Prof. Dr. Edélcio Mostaço e Prof. Dr. Wagner Jonasson da Costa Lima.
} 
Objeto de consideração desde a antiguidade clássica, a memória, já nas primeiras décadas do século XX, integrou as reflexões de Sigmund Freud (1856-1939), Henri Bergson (1859-1941) e Walter Benjamin (1892-1940). Mais recentemente, o assunto foi abordado em vários ensaios pelo crítico cultural alemão Andreas Huyssen (1996). Para o autor, a memória, em si, não opera como recuperação e sim como reapresentação do passado, reapresentação essa que atende, especialmente, as exigências do presente. "O status temporal de qualquer ato da memória é sempre o presente e não, como certa epistemologia ingênua pensa, o próprio passado" (HUYSSEN, 1996, p. 14-15). Além dessa compreensão, Huyssen registrou a ascensão, desde a década de 1980, de um "discurso da memória" nas sociedades ocidentais, fenômeno relacionado, segundo ele, com a crise da ideologia do progresso e com o esgotamento das filosofias finalistas da história. Essa preocupação com a memória e a sua reapresentação manifestou-se, no final do século XX, nos âmbitos político e cultural.

Também na esfera da arte contemporânea notam-se numerosos trabalhos que colocam a memória em destaque, muitos deles servindo-se da fotografia. Nesse cenário da fotografia artística, salientou González Flores (2011, p. 137): “existe uma fotografia não fascinada com o dispositivo mimético, que transcende a imago metonímica e assume plenamente a sua subjetividade". Nesse caso, a fotografia, muitas vezes apreendida como documento ou testemunho, sofreu um processo de "artistificação", funcionando doravante como linguagem expressiva. Dentre os recursos de artistificação encontra-se, historicamente, a alteração da realidade fotografada, a manipulação das técnicas fotográficas e a combinação da fotografia com outras linguagens, como a pintura. A partir das vanguardas históricas, variados artistas investiram contra a disjunção dos meios, adotando um método de trabalho "transgenérico" (GONZÁLEZ FLORES, 2011, p. 178). Como exemplo, pode-se referir a produção de artistas como Paulo Gaiad.

\section{UMA ARTE DA MEMÓRIA}

Nascido em Piracicaba - SP, Paulo Gaiad interessou-se desde cedo pelo desenho e pela pintura, disposição que o levou a optar, aos 19 anos, pelas áreas de arquitetura e urbanismo (CHEREM, 2015). Em 1972, ingressou no curso de Arquitetura e Urbanismo da Universidade de Brasília - UnB, mas logo abandonou os estudos para atuar como arquiteto em sua cidade natal. 
Dois anos depois, matriculou-se no curso de Desenho da Pontifícia Universidade Católica de Campinas - PUC Campinas. Nesse período, Gaiad obteve uma bolsa de estudos para o curso de Planejamento Urbano da Universidade de Oslo, Noruega. Em 1976, recebeu um convite para trabalhar com Vilanova Artigas (1915-1985) em um reconhecido escritório de arquitetura de São Paulo. Na capital paulista, frequentou o curso livre de desenho da Pinacoteca. Mais tarde, já casado e com filho, afastou-se do escritório para exercer a atividade de projetista.

Em 1981, Gaiad fixou residência em Florianópolis como funcionário do Banco do Estado do Rio de Janeiro - Banerj, atuando paralelamente em um escritório de arquitetura para adiante, no final da década, dedicar-se às artes visuais. Segundo depoimento do artista (CHEREM, 2015), a experiência de um passeio de barco ao redor da Ilha de Santa Catarina, em companhia de colegas arquitetos e fotógrafos, contribuiu para essa transição da arquitetura para as artes visuais. Realizada em 1986, a excursão promoveu a súbita produção de grande número de trabalhos que retratavam com traços caligráficos e cores saturadas a paisagem do litoral catarinense. Posteriormente, Gaiad frequentou as Oficinas de Arte do Centro Integrado de Cultura - CIC, espaço vinculado à Fundação Catarinense de Cultura - FCC. Nesse local, sob a orientação de outros artistas, participou de oficinas de desenho e gravura. No final da década de 1980 e início da seguinte, começou a exibir desenhos e pinturas em galerias e salões de arte.

Durante o tempo em que Gaiad voltava-se pouco a pouco para as artes visuais, irrompiam no cenário artístico brasileiro eventos embalados pela revalorização da pintura, depois de período marcado pelas vertentes conceitualistas. Em 1984, por exemplo, a exposição Como vai você, Geração 80?, realizada na Escola de Artes Visuais do Parque Lage (EAV), no Rio de Janeiro, reuniu 126 artistas brasileiros que, no entendimento dos curadores, desejavam produzir "sem os pavores conceituais" (COSTA, 1984). Nesse ajuntamento de artistas e trabalhos encontrava-se, de acordo com o crítico de arte Wilson Coutinho (1984, p. 6), "o neo-expressionismo, o pattern de retorcidas formas coloridas, o rabisco rápido, a pintura agressiva, o mal pintado, o graffitismo, a recaptura da história da arte, a gestualidade agressiva". O evento, a despeito da presença de trabalhos que não se configuravam por meio de recursos exclusivamente pictóricos, tornou-se emblemático da retomada da pintura no país.

Ao longo da década de 1990, Paulo Gaiad adotou expedientes como o "rabisco rápido", "a pintura agressiva" e a "recaptura da história da arte", que se tornaram recorrentes em sua 
produção. Em Paisagem a caminho de Dresden (Figura 1), por exemplo, a linha apresenta-se ora como garatuja desordenada, ora como contorno que conforma árvores, vias, pontes e construções esquemáticas. Esses traços e figuras acham-se sobre manchas de cinza, azul e verde, depositadas com movimentos enérgicos do pincel. Ao lado da fatura ligeira, o título reforça o caráter de notação ou recordação de viagem do trabalho. De acordo com o artista, "ao compor o retrato de uma cidade eu vou juntando momentos e lembranças, anotações feitas na memória, e então passo a montar a 'minha' Berlim, a 'minha' Stuttgart, a 'minha' Dresden” (GAIAD apud MAKOWIECKY, 2009, p. 2722). Aqui, como em outras produções do período, Gaiad reelaborou vivências com o objetivo de produzir nova composição gráfica ou pictórica.

FIGURA 1 - PAULO GAIAD, PAISAGEM A CAMINHO DE DRESDEN, 1995, GRAFITE E GUACHE SOBRE PAPEL, 50.0 X 69.5 CM, COLEÇÃO MUSEU VICTOR MEIRELLES, FLORIANÓPOLIS

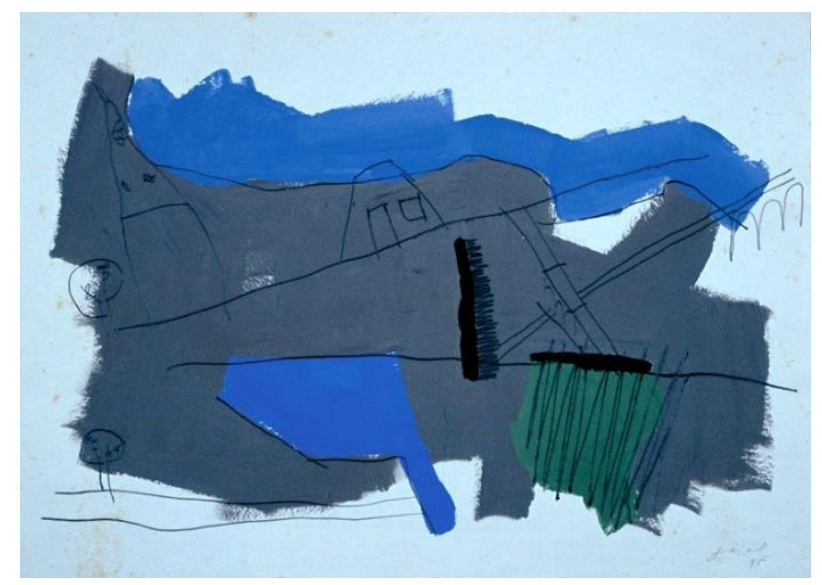

FONTE: MUSEU VICTOR MEIRELLES.

Disponível em: https://museuvictormeirelles.museus.gov.br. Acesso em: 25 jan. 2019.

A partir de 2000, reafirmando e estendendo tema já presente em trabalhos anteriores, a memória e o seu processo de reorganização do sucedido, Gaiad associou com frequência pintura e fotografia. Resultaram desse encontro entre meios de expressão séries como As paredes que me cercam (2003-2007), A divina comédia (2003-2007), Memórias da cozinha (2005), Estudos de luz e sombra (2007), Fragmentos de um Noturno (2008), Desenho das sombras (2009) e After Darkness (2014). Como notou Rosângela Miranda Cherem, que no texto "Sensibilidades biográficas e percepções temporais na obra de Paulo Gaiad" abordou a trajetória e o fazer do artista, a obra de Gaiad distingue-se "por um fluxo onde a imagem e a linguagem se rebatem por meio de distância e 
proximidade, preenchimento e vazio, superfície e profundidade, lembrança e apagamento" (CHEREM, 2015, p. 1). No interior dessa produção, ainda nas palavras de Cherem,

a clave do vivido serve como manancial infinitamente revisitado e estoque movente com força de consignação poética, através do qual reconhece seu repertório, travando uma luta contra o esquecimento e produzindo reverberações para novos trabalhos. (CHEREM, 2015, p. 1).

Essa "luta contra o esquecimento", que mobilizou diferentes meios e procedimentos, mostrou-se em trabalhos reunidos na exposição Impossibilias: arquivo e memória em Paulo Gaiad, realizada na Fundação Cultural Badesc, em Florianópolis, entre os dias 26/11/2015 e 26/02/2016 (EXPOSIÇÃO..., 2015); a última do artista, que faleceu em outubro de 2016. Com curadoria de Cherem, a exposição, que revisitou a trajetória artística de Gaiad e ocupou todas as salas da Fundação, abarcou colagens, desenhos, pinturas, objetos e vídeos. A curadoria agrupou os trabalhos exibidos atentando para três temas que considerou recorrentes na extensa e heterogênea produção do artista: carne (materialidade corporal), passagem (reflexão plástica sobre espaço) e cifra (pequenos segredos biográficos). No título da exposição, contudo, destaca-se o assunto norteador da poética do artista, o da memória, que atravessa diversas séries, como As paredes que me cercam, A divina comédia, Memórias da cozinha e Estudos de luz e sombra, abordadas nas próximas seções.

\section{MEIOS, PROCEDIMENTOS E EFEITOS}

Entre 2003 e 2007, Gaiad produziu um conjunto de pinturas inspiradas na Divina Comédia de Dante Alighieri (1265-1321) e nas gravuras de Gustave Doré (1832-1883) que ilustram o poema (CHEREM, 2015). Embora impelidos pelo épico dantesco e sua iconografia, os trabalhos de Gaiad constituem um universo particular, baseado em registros fotográficos das tragédias e prazeres humanos. Essas imagens, coletadas em livros, revistas e feiras de antiguidades, converteram-se em suporte para os gestos do pintor, adquirindo assim outros sentidos, muitas vezes simbólicos. Nessa situação, o objet trouvé - "qualquer objeto encontrado por um artista e apresentado sem qualquer alteração ou somente com modificações mínimas, como obra de arte" (LUCIE-SMITH, 1990, p. 139) - transformou-se em image trouvée. Intitulada A divina comédia e também dividida em Inferno, 
Purgatório e Paraíso, a série de Gaiad parece reapresentar e reformular, mediante a reunião entre pintura e fotografia, figuras e conteúdo do passado coletivo.

Para realizar a pintura $A$ porta do inferno (Figura 2), que abre e compõe a série Inferno, Gaiad apropriou-se de uma imagem fotográfica da rendição de soldados alemães na Primeira Guerra Mundial (CHEREM, 2015). Ampliada e transposta para uma tela de grandes dimensões, por meio de processo que o artista denominou de "macrofotografia" (BOPPRÉ, 2014), a imagem em preto e branco recebeu econômica intervenção pictórica. No quadro de Gaiad, os prisioneiros amontoados, enquadrados de cima para baixo, têm os rostos ocultados por pequenas manchas de tinta acrílica vermelha, com exceção de dois homens que encaram o observador no centro da fotografia. O gesto pictórico, no caso, comparece como um tipo de "comentário" ao dramático evento histórico. Com toques regulares do pincel, o artista suprimiu, uma a uma, a identidade daqueles que compõem a multidão, em um movimento ascendente de desumanização. Associado às imagens da guerra, o Inferno de Gaiad mostra-se como espaço no qual prevalecem a assimetria de poder e a legitimação da violência.

FIGURA 2 - PAULO GAIAD, A PORTA DO INFERNO, 2007, FOTOGRAFIA, ACRÍLICA E COLAGEM SOBRE TELA, $200 \mathrm{X}$ $140 \mathrm{CM}$, COLEÇÃO PARTICULAR

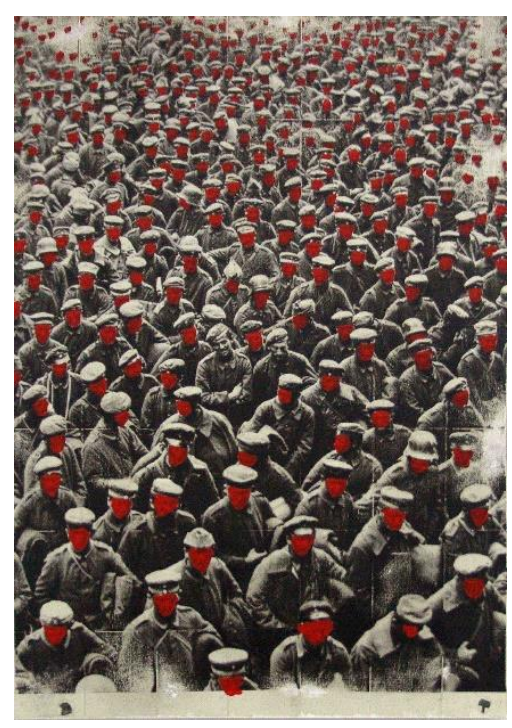

FONTE: LIMA, Fifo. Paulo Gaiad. Florianópolis: Tempo Editorial, 2010.

A série Purgatório, por sua vez, surgiu de uma coleção de fotografias de família, sem identificação, adquirida pelo artista em uma feira de antiguidades em Curitiba - PR (CHEREM, 
2015). Para Gaiad (2007), era significativo o anonimato das pessoas retratadas e o abandono desse conjunto de imagens. Depois de impressas sobre papel jornal "quase podre" (GAIAD, 2007), as fotografias foram cobertas por camada semitransparente de tinta branca, que atenuou detalhes e contrastes das imagens, e fixadas sobre suporte de papelão pardo que estampa a legenda carimbada "Estúdio de Reproduções Fotográficas Ninho do Lagarto - Campeche - Brasil - Lost in Purgatory". Na Figura 3, duas mulheres, vestidas com roupas de décadas passadas, olham e sorriem para o observador, considerando-se a intervenção pictórica sobre a imagem, como se estivessem distanciadas ou encobertas por nevoeiro. Assim, reelaborando aspectos do segundo reino da Divina Comédia de Alighieri, no qual a expiação de faltas passadas constitui a condição para a beatitude, o Purgatório de Gaiad é marcado pela atmosfera nebulosa, indistinta, resultante de sutil ação de apagamento.

FIGURA 3 - PAULO GAIAD, PURGATÓRIO, 2003-2007, TINTA SOBRE PAPEL JORNAL SOBRE PAPELÃO, 36 X 50 CM, COLEÇÃO PARTICULAR

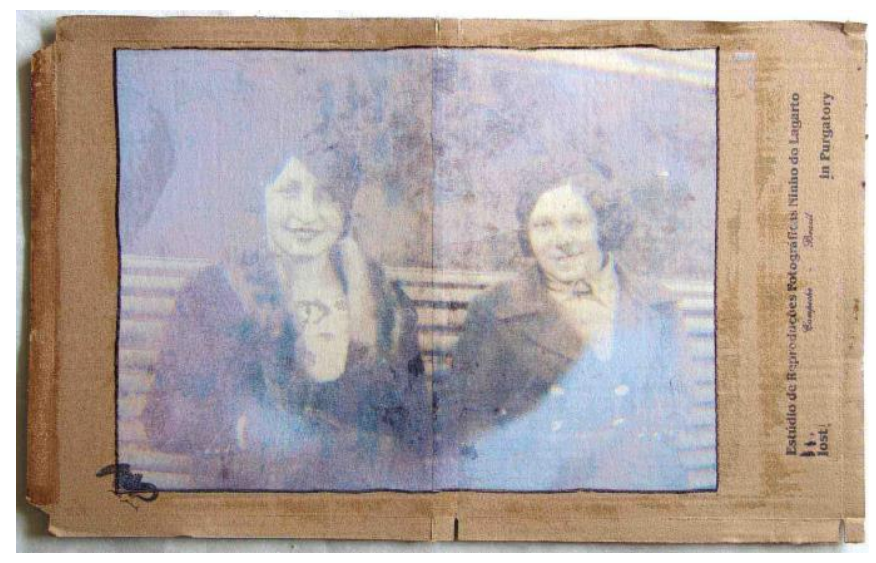

FONTE: Acervo do artista.

Já a série Paraíso teve como ponto de partida o livro Forbidden erótica, que reúne fotografias eróticas dos séculos XIX e XX, todas pertencentes ao colecionador Mark Lee Rotenberg (CHEREM, 2015). Desse acervo de imagens, Gaiad fotografou novamente pormenores que considerou mais sugestivos: um olhar convidativo, uma boca aberta, um toque de mão (Figura 4). Esse movimento em direção ao detalhe eliminou referências espaciais que localizassem as figuras. O primeiríssimo plano, que no âmbito do cinema também destaca um rosto ou amplia um objeto, "lavra um outro tento contra a ordem familiar das aparências" (EPSTEIN, 1983. p. 284). Além disso, 
a proximidade tornou a textura granular da superfície fotográfica mais perceptível, estabelecendo uma espécie de "tato visual", quer dizer, o olhar como prolongamento dos dedos. Posteriormente, as imagens foram impressas sobre papel, afixadas sobre espessas placas de gesso, quebradas e reconstituídas, à maneira de achados arqueológicos. Nesse conjunto de trabalhos, o paraíso, uma vez perdido, foi reconquistado.

FIGURA 4 - PAULO GAIAD, DIVINA COMÉDIA: PARAÍSO, 2004, PAPEL SOBRE GESSO, 78 X 78 CM, COLEÇÃO PARTICULAR

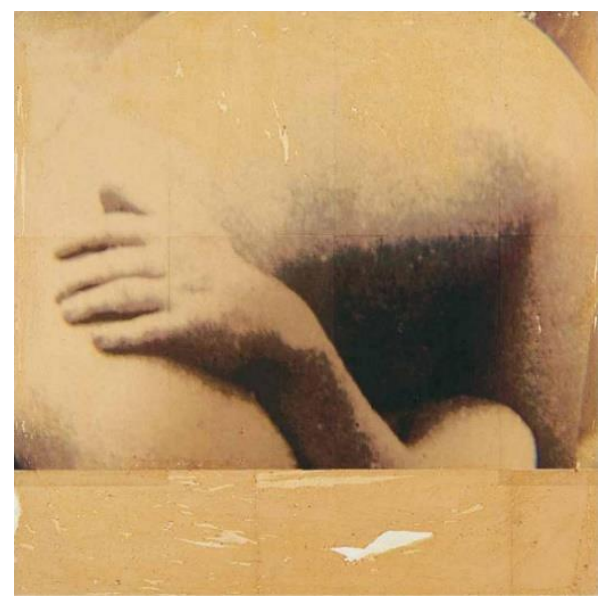

FONTE: LIMA, Fifo. Paulo Gaiad. Florianópolis: Tempo Editorial, 2010.

Em determinadas peças da série Paraíso, além de incisões e rasgos que marcam e desgastam a superfície das imagens, que dessa maneira parecem envelhecidas pelo uso e pelo tempo, o artista empregou expedientes da pintura. No trabalho da Figura 5, composto de tinta, papel e suporte de gesso, toques de magenta retocam a cor dos lábios e as sombras dos olhos de uma figura feminina, enquanto pinceladas palpáveis de azul estabelecem um fundo para a cena. A fotografia, a partir de tais acréscimos, assumiu feição ambígua e arbitrária, visto que não há plena coincidência, mas certo descolamento entre imagem, matéria e cor. Esse efeito decorre, principalmente, do contraste entre a superfície lisa e dessaturada da fotografia e a superfície encorpada e intensa da intervenção pictórica. Ao constituir essa diferença de textura e coloração, Gaiad enfatizou no mesmo suporte o processo tangível de revitalização e, por consequência, de reconstrução da imagem. 
FIGURA 5 - PAULO GAIAD, DIVINA COMÉDIA: PARAÍSO, 2003-2007, TINTA SOBRE PAPEL SOBRE GESSO, 40 X 40 CM, COLEÇÃO PARTICULAR

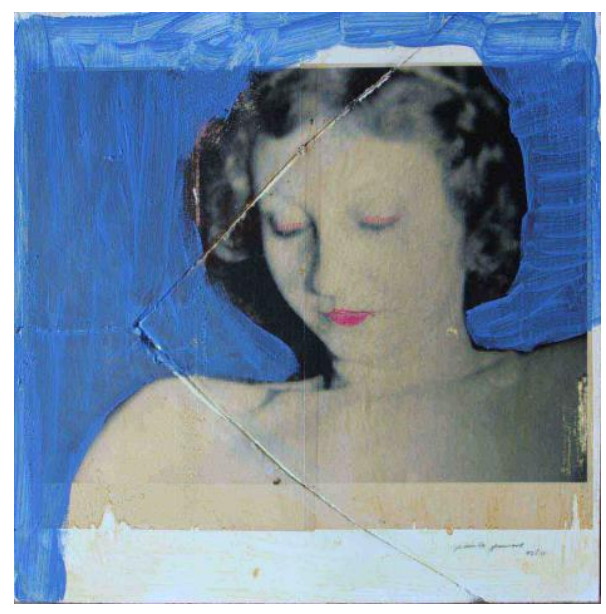

FONTE: Acervo do artista.

A pintura de Gaiad, nessa situação particular, bem como nas séries Inferno e Purgatório, concentrou-se em fazer modificações sobre a imagem apropriada e desse jeito remodelar a sua configuração e sentido. Todavia, cabe notar que a coloração manual de fotografias tornou-se frequente já no século XIX. Normalmente, a sobreposição era justificada pelas "deficiências" da imagem, como, por exemplo, a ausência de cor. Assim surgiu o retoque sobre o negativo ou a cópia (GONZÁLEZ FLORES, 2011). Gaiad, entretanto, não buscou o aperfeiçoamento da fotografia, mas a justaposição de diversos meios de expressão. Dessa maneira, avizinhou-se da produção de artistas como Robert Rauschenberg e Anselm Kiefer. Em comum, o modo de operar que privilegia a "coexistência tensa de diferentes sistemas de signos dentro de um único espaço de representação" (CATTANI, 2006, p. 111). Nessa operação de mestiçagem, na qual concorrem a fotografia e a pintura, o automático e o artesanal, Gaiad substancializou processos como esquecimento e recordação.

\section{APREENDER O MOMENTO FUGIDIO}

Em sua trajetória artística, Gaiad não se restringiu a trabalhos com fortes conotações emblemáticas, como os que integram a série $A$ divina comédia, mas também abordou a pintura de paisagem e a sua tradição. Esse gênero pictórico, que ocupou "os níveis mais baixos da hierarquia de gêneros que dominou a reflexão sobre arte nos séculos XVI e XVII" (MATTOS, 2008, p. 11), ganhou relevância a partir do século XVIII, notadamente com a produção de Caspar David Friedrich 
(1774-1840), William Turner (1775-1851), John Constable (1776-1837), Camille Corot (1796-1875), Camille Pissarro (1830-1903), dentre outros. Em meados do século XIX, a pintura de paisagem, que entre os artistas românticos esteve vinculada à projeção de sentimentos, dirigiu-se progressivamente para a captura do contingente. Na produção de Gaiad, essas poéticas foram agenciadas, reelaboradas e atualizadas por meio da conjunção entre pintura e fotografia. A partir desses materiais, o artista atribuiu concretude à dinâmica entre a passagem do tempo e a atividade da memória.

Por exemplo, na pintura Noturno (Figura 6), realizada em 2003, nuvens delineadas esquematicamente ganham densidade devido ao depósito e acúmulo de materiais como cimento, areia e massa. Construídas sem gradientes de luz e sombra, essas nuvens, de brancura próxima da uniformidade, destacam-se do fundo azul escuro e segmentam a parte superior da tela. Composição e cores lembram o clima dramático e amiúde espiritual de pinturas como $A$ cruz ao lado do Mar Báltico (1815) ou Beira-mar ao luar (1835-1836), de Caspar David Friedrich, importante representante do romantismo alemão. Já na parte inferior da tela, Gaiad tratou de encadear horizontalmente imagens fotográficas em instantes distintos. A partir dessa disposição, nuvens avançam sobre o luar e tem-se quase a sensação de movimento. Desse modo, no mesmo trabalho, o artista estabeleceu um contraste entre a unicidade da pintura e a multiplicidade da fotografia, entre sucessão de acontecimentos e fixação desses acontecimentos, entre o ocorrido e a rememoração.

FIGURA 6 - PAULO GAIAD, NOTURNO, 2003, CIMENTO, AREIA, MASSA E FOTOGRAFIA SOBRE TELA, 200 X 140 CM, COLEÇÃO PARTICULAR

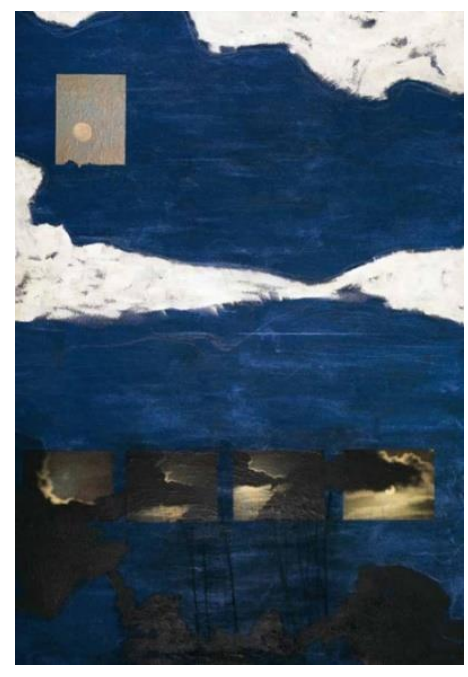

FONTE: LIMA, Fifo. Paulo Gaiad. Florianópolis: Tempo Editorial, 2010. 
A associação entre pintura de paisagem e imagem fotográfica encontra-se também em trabalhos como Céu de Delft I e Céu de Delft II, ambos pertencentes à série Estudos de luz e sombra e elaborados depois da visita de Gaiad à cidade holandesa (GAIAD, 2007). A viagem decorreu da participação em 2006 no projeto Pintar um Futuro (PAINT A FUTURE, 2019), concebido pela artista Hetty van der Linden. Após tomar parte no projeto, que visa promover o bem-estar de crianças carentes ao redor do mundo, Gaiad foi convidado para diversos eventos na Europa, como residências e exposições. Durante a breve excursão a Delft, de um dia, espantou-se com as repentinas mudanças do clima e sobretudo do aspecto do céu. Como declarou em entrevista, "ele tem uma movimentação muito rápida, tá limpo, daqui a pouco fecha, chove, limpa de novo" (GAIAD, 2007). Impressionado pelo fenômeno, o artista realizou vários registros fotográficos que mais tarde foram selecionados e transpostos para a superfície de duas telas. Em seguida, iniciou o trabalho com as tintas, complementando e alterando as imagens capturadas.

A pintura Céu de Delft I/ (Figura 7), por exemplo, mostra a imagem da silhueta da cidade telhados, postes, pináculos - contra um acumulado de nuvens modeladas pela luz. Manchas opacas de azul escuro e camadas transparentes de cores terrosas, realizadas com a tinta acrílica, completam e alteram a vista. Abaixo, pinceladas largas, juntamente com escorridos, respingos e rasgos, ocupam ampla área do quadro. A linha do horizonte elevada, próxima à borda superior do quadro, sublinha a passagem de uma visualidade fotográfica e sua dimensão especular para uma gestualidade informal e seu investimento na matéria. Dessa maneira, pode-se acompanhar a transição da figuração para a não figuração, do determinado para o indeterminado, do registro para a reminiscência. A pintura formulou-se somente depois que o artista prolongou e reafirmou, com base nos elementos fornecidos pela fotografia, as suas percepções e afetos. 
FIGURA 7 - PAULO GAIAD, CÉU DE DELFT II, 2007, FOTOGRAFIA, ACRÍLICA E COLAGEM SOBRE PAPEL SOBRE TELA, $200 \mathrm{X}$ 140 CM, COLEÇÃO PARTICULAR

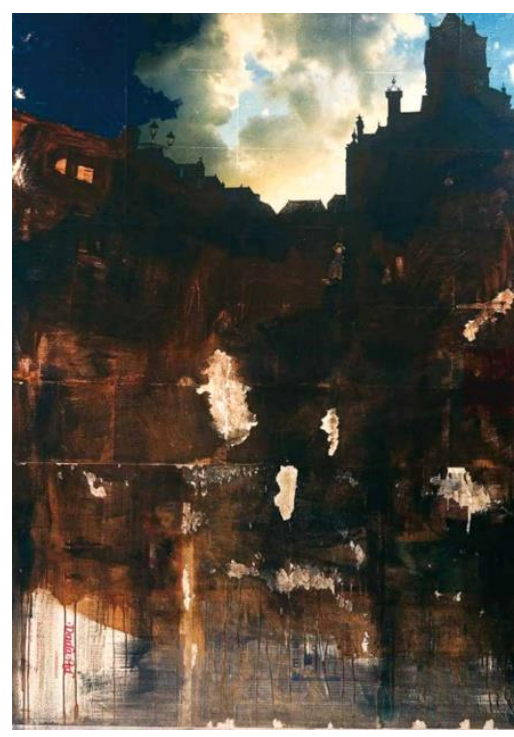

FONTE: LIMA, Fifo. Paulo Gaiad. Florianópolis: Tempo Editorial, 2010.

Com as suas nuvens e o seu tratamento vigoroso, Céu de Delft // faz menção deliberada à pintura de paisagem holandesa do século XVII e, consequentemente, à produção de William Turner e John Constable. Como observou Kenneth Clark, nas telas de Jacob van Ruisdael (1628-1682), principal expoente da fase clássica da pintura de paisagem holandesa, "as nuvens acumulam-se no espaço, as sombras navegam através de planícies" (CLARK, 1961, p. 54). Esse sentido de mobilidade dos elementos naturais tornou-se modelo para toda uma escola pictórica da Inglaterra do final do século XVIII e início do seguinte. Entre 1821 e 1822, Constable pintou cerca de 100 estudos a óleo de céus em diversas condições, observando formações de nuvens e seus deslocamentos. Estudioso da tradição e atento observador da natureza, o pintor inglês alegou que sua arte visava ao "breve momento arrancado ao tempo fugidio para uma existência permanente e sóbria" (CONSTABLE apud GOMBRICH, 2007, p. 325).

Em suas paisagens, Paulo Gaiad parece também cultivar o desejo de captura do efêmero, o que revela afinidade com a poética romântica, caracterizada pelo culto à natureza e à imaginação, assim como pela experiência da "caducidade do tempo", na qual "o eterno desaparecer e morrer parecem infinitos" (PAZ, 1992, p. 52). Ao mesmo tempo, o artista foi informado pela fotografia, cinema e televisão da mesma maneira que uma geração de pintores que iniciaram as suas atividades nas décadas de 1970 e 1980. A partir daí, numerosos artistas lidaram com "um universo 
de informações fragmentado, cheio de imagens das mais diversas épocas e procedências" (CHIARELLI, 2001, p. 265), cada qual à sua maneira, dependendo dos modelos selecionados. Em Noturno e Céu de Delft II, o uso de cenas fotográficas diferencialmente articuladas, ao lado de referências à tradição da pintura de paisagem, apresenta-se como uma solução encontrada por Gaiad para figurar as relações entre o instante que passa e a lembrança que o reelabora.

\section{A TRANSITORIEDADE DE TODAS AS COISAS}

Além da pintura de paisagem, outros gêneros pictóricos tradicionais, como a natureza-morta, serviram ao propósito de Gaiad de materializar o processo mnemônico. A natureza-morta, na acepção de Meyer Schapiro (2010. p. 61), "consiste de objetos que, sejam artificiais ou naturais, estão subordinados ao homem como elementos de uso, manipulação e prazer". Desde a sua afirmação como gênero autônomo no século XVII, a natureza-morta engajou pintores na representação de aspectos singulares de objetos corriqueiros. A princípio de aparência banal, esses objetos, ampulhetas, castiçais, livros, cálices tornaram-se motivo de divagação metafísica nas vanitas, tipo de pintura voltada para a ponderação sobre a transitoriedade de todas as coisas que se desenvolveu plenamente nos Países Baixos a partir de 1600. Nos quadros de Gaiad, a natureza-morta, a pintura e a fotografia aparecem como materiais que contribuem para a concretização do entrelace entre falta e recordação.

Sob esse viés, pode-se destacar a tela As Paredes que me Cercam (Figura 8), concebida em torno da fotografia de um copo que evoca, com o seu brilho e a sua disposição, a pintura de JeanBaptiste-Siméon Chardin (1699-1779), artista reconhecido por naturezas-mortas como $O$ pote de azeitonas (1760), cuja técnica era capaz de manifestar, na visão de Denis Diderot (2006. p. 90), “a própria substância dos objetos". Abaixo da imagem fotográfica, Gaiad esboçou com pinceladas rápidas uma toalha de mesa branca que se destaca do fundo composto de uma superfície marrom e de grandes manchas verdes escuras. A partir de recursos pictóricos, o artista fez coincidir a imagem do copo e o objeto fotografia, ambos apoiados arbitrariamente sobre um tampo inacabado. Nessa lógica, a pintura de Gaiad contém simultaneamente uma referência ao mundo

cotidiano e um fragmento desse mundo na composição do quadro. Juntas, pintura e fotografia instauram um jogo de ausência e presença. 
FIGURA 8 - PAULO GAIAD, AS PAREDES QUE ME CERCAM, 2003, FOTOGRAFIA, ACRÍLICA E COLAGEM SOBRE TELA, $120 \mathrm{X}$ $150 \mathrm{CM}$, COLEÇÃO PARTICULAR
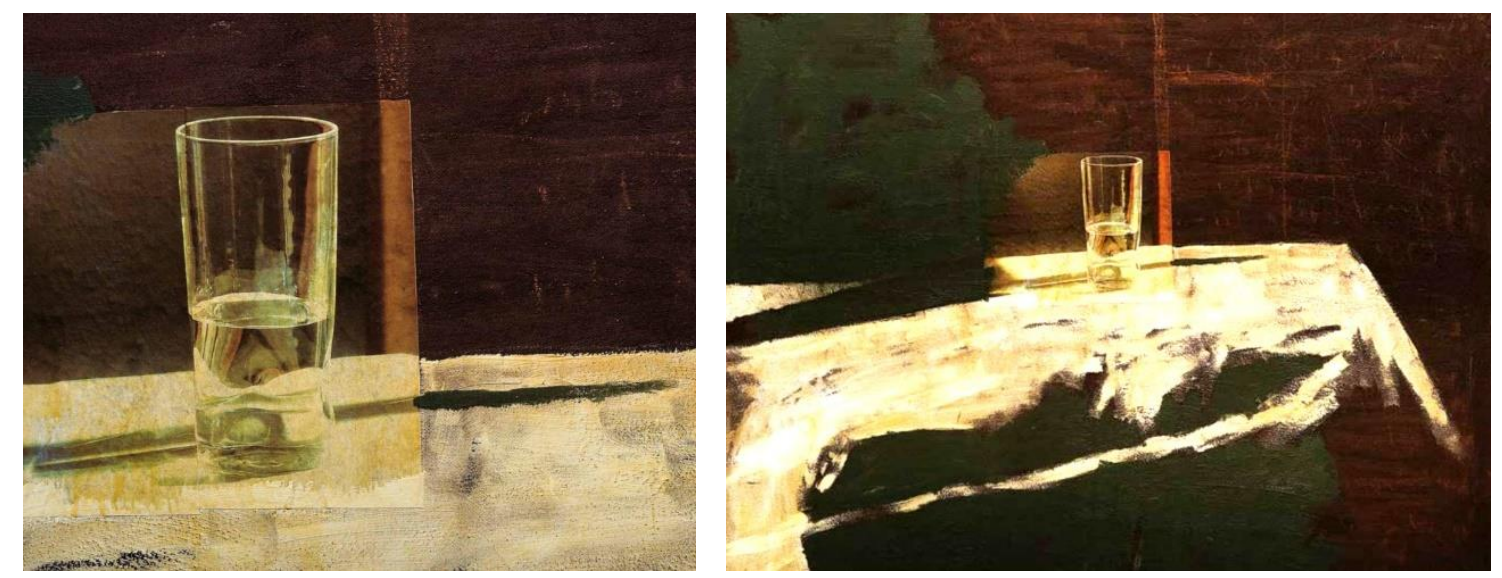

FONTE: LIMA, Fifo. Paulo Gaiad. Florianópolis: Tempo Editorial, 2010.

Em outros trabalhos de Gaiad, a natureza-morta coloca-se de modo mais explícito como veículo para a memória autobiográfica e para a meditação sobre a finitude. É o caso de Memória da cozinha (Figura 9), pintura em que o artista elaborou, a partir da mesa que pertenceu à sua família e de objetos pessoais, as suas recordações da infância (LIMA, 2010). Os utensílios escolhidos e fotografados - as cadeiras, a mesa, a comida, a bebida, a louça - remetem ao doméstico e ao convival, sugerindo um anseio de restauração da ordem familiar. Simultaneamente, sob uma atmosfera simbólica, congênere àquela encontrada nas vanitas do século XVII, tais objetos comparecem como lembranças do efêmero e da morte. Em meio a esse simbolismo, rasgos e borrões de tinta degradam e lambuzam a superfície da imagem, promovendo um contraponto entre inclusão e exclusão do observador, entre profundidade e anteparo. Nessas condições, o quadro enseja a sobreposição de sinais emblemáticos da passagem do tempo e de sinais concretos da realização do trabalho. 
FIGURA 9 - PAULO GAIAD, MEMÓRIA DA COZINHA, 2007, FOTOGRAFIA, ACRÍLICA E COLAGEM SOBRE TELA, 140 X 140 CM, COLEÇÃO PARTICULAR

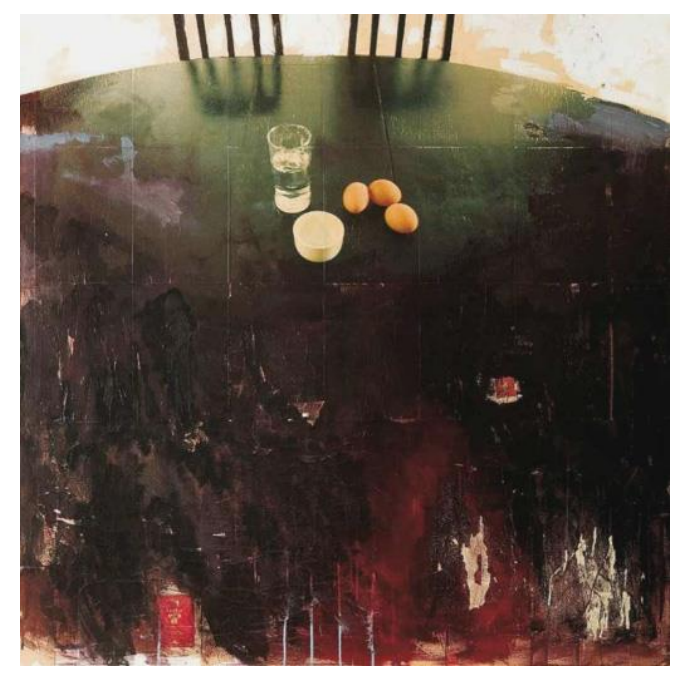

FONTE: LIMA, Fifo. Paulo Gaiad. Florianópolis: Tempo Editorial, 2010.

Em As paredes que me cercam e Memória da cozinha, Gaiad parece propor vias de contato, sem desconsiderar o "anti-ilusionismo" da arte moderna, entre a tradição da natureza-morta e a mestiçagem da pintura contemporânea. No início do século XX, Pablo Picasso (1881-1973) salientou a concretude de suas naturezas-mortas agregando recortes de jornal à tela, entre outros materiais, ao lado da tinta a óleo tradicional, não raro misturada com areia. Tanto a colagem quanto o efeito de textura áspera indicam o interesse dos cubistas pelo quadro como objeto e não como janela. Posteriormente, Jasper Johns (1930-), nas décadas de 1950 e de 1960, incluiu utensílios familiares uma vassoura, uma xícara, uma lanterna, um prato - em Fool's house (1962) e Souvenir (1964), trabalhos que atenuam os limites entre o espaço cotidiano e o espaço pictórico. Tal como Picasso e Johns, Paulo Gaiad, ao adotar a lógica agregadora da colagem e da assemblagem, transformou o plano da pintura, e de suas naturezas-mortas, em um amontoamento heteróclito de materiais que exibem as suas qualidades.

No interior desse amálgama denso estabelecido por Gaiad, a fotografia, junto à pintura, cumpriu importante papel, tanto constitutivo quanto significativo. Em muitas ocasiões, o artista iniciou seus trabalhos a partir de imagem fotográfica fixada sobre a superfície do quadro, modificando a sua configuração, textura e cor. Contudo, em telas como As paredes que me cercam, ou mesmo Memória da cozinha, a fotografia apresentou-se não apenas como imagem que provoca 
e dirige a ação do pintor, mas como objeto de manipulação. Nesse sentido, possui materialidade e, tal como outros objetos, está sujeita à deterioração. Esse processo entrópico, no qual a organização caminha para a desorganização e, em seguida, para a ruína, parece acelerar-se, no caso de Memória da cozinha, a partir da intervenção pictórica. A tinta acrílica, que produz grumos, escorridos e logo depois rasgões, corrompe a superfície homogênea e maquinal da imagem fotográfica.

\section{CONSIDERAÇÕES FINAIS}

Surgida no século XIX como máquina de produzir imagens de captura, a fotografia, no transcorrer do século $\mathrm{XX}$, foi admitida decididamente na esfera da pintura, notadamente em produções de artistas contemporâneos como Robert Rauschenberg, Anselm Kiefer e também, a partir de 2000, Paulo Gaiad. Tanto Rauschenberg quanto Kiefer investiram, em situações distintas, contra a disjunção das artes, adotando um modo de operar "transgenérico", no qual se valoriza a conjunção de meios. À semelhança desses pintores, Gaiad levou em conta, na construção de seus quadros, a coexistência entre o pictórico e o fotográfico. Todavia, de acordo com declarações do artista brasileiro, essa associação serviu principalmente ao seu propósito, ou projeto poético, de tratar da memória como recriação do ocorrido, tema que alicerça o seu trabalho artístico.

Na série $A$ divina comédia, por exemplo, imagens fotográficas preexistentes, coletadas em livros, revistas e feiras de antiguidades transformaram-se em suporte para o trabalho do pintor. Em tal situação, na qual a superfície da fotografia recebeu a matéria pictórica, o artista, a partir de ocultamentos, transparências e contrastes de textura e cor, alterou a aparência e, por conseguinte, o sentido das imagens recolhidas. Dessa maneira, a série de Gaiad, desenvolvida entre os anos de 2003 e 2007, recolocou figuras e reorganizou conteúdo do passado. Nessa operação de reelaboração do sucedido, que envolveu a "mestiçagem" - justaposição de diferentes meios no interior de determinado espaço de representação - Gaiad tornou sensíveis e tateáveis processos imateriais, reconhecidamente subjetivos, como a recordação e o esquecimento.

Para levar adiante esse projeto de materialização do mnemônico, Gaiad convocou ainda a tradição da pintura, recorrendo a gêneros já repertoriados pela história da arte, como a paisagem e a natureza-morta, e os seus conteúdos. Em suas paisagens, que remetem em alguns momentos à 
pintura holandesa e romântica, o artista tratou das relações entre instante e lembrança. Já em suas naturezas-mortas, que exibem atmosfera simbólica semelhante àquela encontrada nas vanitas do século XVII, das relações entre falta e recordação. Nesses casos, gêneros reconhecidos, e as suas iconografias características, foram utilizados como materiais, ao lado da pintura e da fotografia, na concretização do que o artista concebe como memória. E como na série A divina comédia, a imagem fotográfica ganhou outra tessitura depois de submetida aos recursos pictóricos.

Nessa perspectiva, além de orientado pelo tema da memória como recriação, o projeto poético de Gaiad associou-se às práticas artísticas ditas "contemporâneas", isto é, aquelas que se afastam do preceito segundo o qual cada arte caminharia progressivamente para uma depuração dos elementos que não Ihe são essenciais. Quando se trata da produção de pintores contemporâneos, como a de Paulo Gaiad, é possível encontrar uma desconcertante profusão de programas de arte e nos quais não há nenhum material que desfrute da prerrogativa de ser prontamente reconhecido como material para a pintura. A contaminação da pintura por outros meios, como a fotografia, produziu um novo cenário artístico, abalizado por relações de comunidade e não de exclusão.

\section{REFERÊNCIAS}

BOPPRÉ, F. Apontamentos sobre um olhar do crítico. In: PUNCTUM. Florianópolis : UFSC, 10 . dez. 2014. Disponível em: http://www.punctum.ufsc.br/?p=2287. Acesso em: 25 jan. 2019.

CATTANI, I. B. Cruzamentos e tensões: mestiçagens na arte contemporânea no Brasil e no Canadá. Interfaces Brasil/Canadá, Pelotas, v. 6, n. 1, p. 109-130, 2006. Disponível em: https://periodicos.ufpel.edu.br/ojs2/index.php/interfaces/article/view/6920. Acesso em: 19 fev. 2019.

CHEREM, R. M. Sensibilidades biográficas e percepções temporais na obra de Paulo Gaiad. In: SIMPÓSIO NACIONAL DE HISTÓRIA, 28., 2015, Florianópolis. Anais eletrônicos [...] Florianópolis: UFSC/UDESC, 2015. p. 1-16. Disponível em: http://www.snh2015.anpuh.org/resources/anais/39/1434396861_ARQUIVO_Sensibilidadesbiogra ficasepercepcoestemporaisnaobradePauloGaiad.pdf. Acesso em: 25 jan. 2019.

CHIARELLI, T. Considerações sobre o uso de imagens de segunda geração na arte contemporânea. In: BASBAUM, R. (org.). Arte contemporânea brasileira: texturas, dicções, ficções, estratégias. Rio de Janeiro: Rios Ambiciosos, 2001. p. 257-270. Disponível em: 
https://esgotadoarquivo.files.wordpress.com/2018/05/282646798-arte-contemporaneabrasileira.pdf. Acesso em 26 jan. 2019.

CLARK, K. Paisagem na arte. Lisboa: Ulisseia, 1961.

COSTA, M. L. A Bela enfurecida. In: MemoriaLage. Coleção Marcus Lontra (1983-1987) .Rio de Janeiro : Escola de Artes Visuais do Parque Lage, 14 jul. 1984. 1 Cartaz, color., 43,9 x 31,0 cm . Disponível em: https://www.memorialage.com.br/marcus-lontra/. Acesso em: 10 jan. 2019.

COUTINHO, W. Festa e democracia na arte do Parque Lage. Jornal do Brasil, Rio de Janeiro, 23 jul. 1984. Caderno B, p. 6.

DIDEROT, D. Salão de 1763. In: LICHTENSTEIN, Jacqueline (org.). Os Gêneros pictóricos. São Paulo: Ed. 34, 2006. p. 89-91. ( A Pintura: textos essenciais, 10)

EPSTEIN, J. A inteligência de uma máquina - excertos. In: XAVIER, I. (org.). A experiência do cinema: antologia. Rio de Janeiro: Graal, 1983. p. 283-292. (Coleção Arte e Cultura, 5). Disponível em: https://www.academia.edu/7047622/38145313_Ismail_Xavier_A_Experiencia_Do_Cinema. Acesso em: 21 jan. 2019.

GAIAD, P. A Cor da nossa tela: Paulo Gaiad. [Entrevista cedida a] TV UFSC. Direção: Zeca Pires. Florianópolis, 2015. 1 vídeo (4min.27s). Publicado pelo canal TV UFSC no YouTube. Disponível em: https://www.youtube.com/watch?v=4ek53mFmR08. Acesso em: 25 jan. 2019.

GAIAD, P . Mariana de Abreu entrevista o artista plástico Paulo Gaiad. [Entrevista cedida a] Mariana de Abreu Bastian , 20vê, TVCOM/RBS, Florianópolis, 2007. 1 vídeo (12min.49s). Publicado pelo canal Mariana de abreu bastian no YouTube. Disponível em:

https://www.youtube.com/watch?v=s19aQo41fSY. Acesso em: 25 jan. 2019.

EXPOSIÇÃO Impossibilias: arquivo e memória em Paulo Gaiad. Florianópolis : Fundação Cultural Badesc, 26 nov. 2015. Disponível em: https://fundacaoculturalbadesc.com/exposicao-de-paulogaiad-revisita-sua-trajetoria-artistica-e-ocupa-pela-primeira-vez-todos-os-espacos-da-fundacaocultural-badesc/. Acesso em: 25 jan. 2019.

GOMBRICH, E. H. Arte e ilusão: um estudo da psicologia da representação pictórica. São Paulo: WMF Martins Fontes, 2007.

GONZÁLEZ FLORES, L. Fotografia e pintura: dois meios diferentes? São Paulo: WMF Martins Fontes, 2011.

HUYSSEN, A. Memórias do modernismo. Rio de Janeiro: UFRJ, 1996.

LIMA, F. Paulo Gaiad. Florianópolis: Tempo Editorial, 2010.

LUCIE-SMITH, E. Dicionário de termos da arte. Lisboa: Dom Quixote, 1990. 
MAKOWIECKY, S. Paulo Gaiad - Artista - Viajante. In: ENCONTRO ASSOCIAÇÃO NACIONAL DE PESQUISADORES EM ARTES PLÁSTICAS, 18., 2009, Salvador. Anais eletrônicos [...] Salvador: EDUFBA, 2009. p. 2717-2731. Disponível em:

http://anpap.org.br/anais/2009/pdf/chtca/sandra_makowiecky.pdf. Acesso em: 25 jan. 2019.

MATTOS, C. V. de (org.). Goethe e Hackert: sobre a pintura de paisagem: quadros na natureza na Europa e no Brasil. Cotia: Ateliê Editorial, 2008.

PAINT A FUTURE. 2019. Disponível em: www.paintafuture.org. Acesso em: 25 jan. 2019.

PAZ, A. de. La revolución romántica: poéticas, estéticas, ideologías. Madrid: Tecnos, 1992.

ROUILLÉ, A. A fotografia: entre documento e arte contemporânea. São Paulo: Senac, 2009.

SALLES, C. A. Gesto inacabado: processo de criação artística. São Paulo: Annablume, 2011.

SANTAELLA, .L; NÖTH, W. Imagem: cognição, semiótica, mídia. São Paulo: Iluminuras, 1998.

SCHAPIRO, M. As maçãs de Cézanne: um ensaio sobre o significado da natureza-morta. In: SCHAPIRO, M. A arte moderna: séculos XIX e XX : ensaios escolhidos. São Paulo: Editora da Universidade de São Paulo, 2010. p. 33-77.

STEINBERG, L. Outros critérios. In: STEINBERG, L. Outros critérios: confrontos com a arte do século XX. São Paulo: Cosac Naify, 2008. p. 79-125. 